\title{
ANALISIS ANTRIAN KAPAL DI DERMAGA 5 PELABUHAN BANTEN
}

\author{
Nugraheni Djamal, Haris Eno Maulana \\ Program Studi Teknik Industri, Fakultas Teknik, Universitas Serang Raya \\ Email: nugraheni.dj@gmail.com; harisenomaulana@gmail.com.
}

\begin{abstract}
Abstrak - Pelabuhan Banten adalah suatu perusahan yang bergerak di bidang jasa pelabuhan di Indonesia yang salah satu aspek pentingnya adalah proses bongkar muat kapal yang merupakan bagian dari proses labuh yang akan mempengaruhi antrian kapal masuk atau keluar dari pelabuhan. Dalam hal ini, variabel yang diamati adalah data waktu antar kedatangan, waktu pelayanan, dan jumlah pelayanan. Metode yang digunakan dalam pengambilan sempel data waktu antar kedatangan adalah sampling purposive. Metode analisis data meliputi pendeteksian distribusi data, penentuan model antrian, dan penghitungan performansi model antrian. Sistem antrian multi channel single phase yang digunakam di Pelabuhan Banten untuk rata-rata kedatangan kapal $(\lambda)$ diperoleh 45 kapal/bulan dan rata-rata pelayanan $(\mu)$ menambahkan 2 server, dari 3 server menjadi 5 server dikarenakan dari perhitungan 5 server didapat didapatkan hasil dari perhitungan model antrian didapatkan hasil Probabilitas tidak ada pelayanan ( $P$ o) adalah 0,023, Rata-rata jumlah menunggu dalam antrian (Lq) adalah 26 kapal, Rata-rata jumlah menunggu dalam sistem (Ls) adalah 35 kapal, Rata-rata waktu menunggu dalam antrian (Wq) adalah 34,66 menit, Rata-rata waktu menunggu dalam sistem (Ws) adalah 35,99 menit.
\end{abstract}

Kata kunci: Antrian; Jumlah Pelayanan; Waktu Pelayanan

\begin{abstract}
Pelabuhan Banten is a company engaged in port services in Indonesia, one of the essential aspects of which is the process of loading and unloading ships which are part of the landing process that will affect the queue of vessels entering or exiting the port. In this case, the variables observed were data on the time of arrival, service time, and the number of services. The method used in the retrieval of data on arrival time is purposive sampling. Data analysis methods include the detection of data distribution, determination of the queue model, and performs the calculation of the queue model. The single phase multichannel queuing system used in Banten Port for the average arrival of ships $(\lambda)$ is obtained 45 ships/month and the average service $(\mu)$ adds 2 servers, from 3 servers to 5 servers because of the calculation of the 5 servers obtained the results of the calculation of the queue model are obtained. The probability of no service $(P O)$ is 0.023 . The average number of waiting in the queue (LQ) is 26 ships. The average number of waits in the system (Ls) is 35 ships. Average waiting time in the queue $(W q)$ is 34.66 minutes, the average waiting time in the system (Ws) is 35.99 minutes..
\end{abstract}

Keywords: Queue; Number of Services; Service Time

\section{PENDAHULUAN}

Indonesia merupakan salah satu negara kepulauan terbesar di dunia yang memiliki sekitar 13.487 pulau, yang terpisah oleh laut. Sehingga diperlukan sarana dan prasarana laut dengan baik yaitu kapal laut dan pelabuhan. Pelabuhan sebagai tempat peralihan antar moda transportasi darat dan laut yang memiliki peran yang sangat penting dan strategis dalam menunjang perekonomian nasional dan daerah. Pelayanan kapal di pelabuhan terdapat pelayanan labuh, pemanduan, tunda, penambatan, bunkering, dan naik turun penumpang.
Pelabuhan Banten adalah satu cabang perusahan yang bergerak di bidang jasa pelabuhan di Indonesia. Salah satu aspek penting pada setiap dermaga di Pelabuhan Banten adalah proses bongkar muat kapal yang merupakan bagian dari proses labuh yang akan mempengaruhi antrian kapal masuk atau keluar dari pelabuhan. Sering kali dalam proses bongkar muat mengalami keterlambatan yang disebabkan oleh berbagai hal di antaranya proses sandar kapal yang belum tepat waktu, kurangnya koordinasi dalam proses bongkar muat, tidak adanya ship crane sarana pengangkut yang kurang efektif, kendala 
penambatan dan lain sebagainya. Keterlambatan proses bongkar muat akibat antrian yang panjang menyebabkan beberapa hal diantaranya barangbarang yang diangkut tidak datang tepat waktu dan juga menambah biaya sandar kapal.

Di dermaga Pelabuhan Banten sering terjadi antrian atau penumpukan kapal sehingga diperlukannya pengaturan penjadwalan kapal masuk dan kapal keluar secara baik sehingga tidak akan lagi terjadinya penumpukan antrian pada kapal yang akan masuk pada dermaga.

Tabel 1. Jumlah kapal yang berlabuh di dermaga tahun 2016

\begin{tabular}{lccccccc}
\hline Bulan & dermaga & dermaga & dermaga & dermaga & dermaga & dermaga & dermaga \\
& 1 & 2 & 3 & 4 & 5 & 6 & 7 \\
\hline Januari & 10 & 20 & 0 & 11 & 45 & 3 & 17 \\
Februari & 9 & 11 & 0 & 20 & 52 & 0 & 7 \\
Maret & 8 & 21 & 2 & 7 & 51 & 1 & 15 \\
April & 4 & 14 & 0 & 20 & 46 & 0 & 12 \\
Mei & 7 & 13 & 0 & 20 & 53 & 2 & 13 \\
Juni & 3 & 20 & 1 & 16 & 51 & 0 & 9 \\
Juli & 5 & 12 & 2 & 15 & 30 & 2 & 11 \\
Agustus & 3 & 15 & 1 & 21 & 35 & 3 & 20 \\
September & 3 & 16 & 0 & 20 & 39 & 3 & 25 \\
Oktober & 4 & 19 & 0 & 19 & 45 & 2 & 16 \\
November & 5 & 14 & 1 & 17 & 39 & 1 & 14 \\
\hline
\end{tabular}

Dari Tabel 1 terlihat dermaga 5 adalah dermaga yang paling sibuk. Hal ini mengakibatkan kapal membutuhkan waktu yang cukup lama dalam menunggu giliran untuk mendapatkan pelayanan. Berdasarkan kondisi tersebut dan dengan menyadari arti pentingnya pelayanan yang lebih baik kepada pelanggan maka perlu adanya perbaikan kinerja dari proses pelayanan yang mempunyai sifat ketidakpastian. Akan diteliti mengenai jumlah optimal stasiun dermaga untuk melayani kapal tertambat supaya dapat meminimasi tingkat kepadatan kapal yang berlabuh.

Antrian adalah deret tunggu di dalam sebuah sistem dari unit-unit yang ingin memperoleh pelayanan dari suatu fasilitas pelayanan; tujuan dari penggunaan teori antrian adalah untuk merancang fasilitas pelayanan, untuk mengatasi permintaan pelayanan yang berfluktuasi secara random dan menjaga keseimbangan antara biaya pelayanan dan biaya yang diperlukan selama antrian (Subagyo dkk., 1983). Proses antrian dimulai pada saat pelanggan yang memerlukan pelayanan mulai datang, mereka berasal dari sebuah populasi yang disebut sumber masukan. Proses antrian sendiri merupakan suatu proses yang berhubungan dengan kedatangan pelanggan pada suatu fasilitas pelayanan, menunggu dalam baris tunggu jika belum dapat dilayani, dilayani dan akhirnya meninggalkan fasilitas tersebut sesudah dilayani. Sedangkan sebuah sistem antrian adalah suatu campuran pelanggan, pelayan dan aturan yang mengatur kedatangan pelanggan dalam pemprosesan masalah (Bronson, 1993).

Metode antrian dapat diaplikasikan dalam berbagai industri maupun jasa seperti pada jasa perbankan (Harahap, Sinulingga, \& Ariswoyo, 2014; Arwindy, Bu'ulolo, \& Rosmaini, 2014). Produksi (Baroto, 2010), SPBU (Tinambunan, 2017), Bandara (Sari, 2013) maupun industri lainnya. Penelitian ini bertujuan untuk menganalisa sistem antrian yang ada di Pelabuhan Banten untuk mendapatkan sistem pelayanan yang efektif berdasarkan jumlah pelayanan yang harus disediakan.

\section{METODE PENELITIAN}

Penelitian dilakukan di Dermaga 5 Pelabuhan Banten. Berdasarkan jenis aktivitasnya, antrian kapal berlabuh memiliki model antrian pelayanan ganda dengan populasi tak terbatas $(\mathrm{M} / \mathrm{M} / \mathrm{c}):(\mathrm{GD} / \infty / \infty)$, di mana
$P_{n} \quad$ : Probabilitas dari $n$ pelanggan dalam sistem
M : Jumlah kedatangan berdistribusi Poisson
M : Waktu pelayanan berdistribusi Poisson atau berdistribusi Eksponensial 
c : Jumlah server, Multichannel (pelayanan ganda)

GD : FIFO (First In First Out)

$\infty$ : Antiran dan sumber kedatangan tak terhingga

Persamaan-persamaan yang ada pada Model Antrian Pelayanan Ganda dengan Populasi Tidak Terbatas adalah sebagai berikut (Levin, et,al., 2002):

1. Probabilitas tidak ada pelayanan

$$
P_{0}=\frac{1}{\left[\sum_{n=0}^{s-1} \frac{\left(\frac{\lambda}{\mu}\right)^{n}}{n !}\right]+\frac{\left(\frac{\lambda}{\mu}\right)^{c}}{c !\left(1-\frac{\lambda}{c \cdot \mu}\right)}}
$$

2. Rata-rata jumlah menunggu dalam antrian

$$
L_{q}=\frac{\lambda \cdot \mu\left(\frac{\lambda}{\mu}\right)^{c}}{(c-1) !(c \cdot \mu-\lambda)^{2}} P_{0}
$$

3. Rata-rata jumlah menunggu dalam sistem

$$
L_{s}=L_{q}+\frac{\lambda}{\mu}
$$

4. Rata-rata waktu menunggu dalam antrian

$$
W_{q}=\frac{L_{q}}{\lambda}
$$

5. Rata-rata waktu menunggu dalam sistem

$$
W_{s}=W_{q}+\frac{1}{\lambda}
$$

\section{HASIL DAN PEMBAHASAN}

Istilah kegiatan dalam PT. Pelabuhan Indonesia II (Persero) Cabang Banten :

1. FIFO (First In First Out) yaitu kedatangan pelanggan pertama menerima pelayanan lebih dahulu.

2. Kedatangan (arival) datangnya pelanggan (barang) untuk dilayani mengikuti distribusi poisson bebas kedatangan sebelum atau sesudah.

3. Waktu Pelayanan : Lama pelayanan sampai selesai.

4. Waktu Menunggu : Waktu menunggu untuk dilayani atau waktu menunggu selama dalam sistem.
5. Permintaan Pelayanan Jasa $(P P J)=$ Pelanggan $=$ Customer

6. Pemberi Pelayanan $(P P)=$ Server (Orang/Operator : Barang atau Mesin Otomatis).

7. Rata-rata Kedatangan (RKK) banyaknya kedatangan SPP persatuan waktu.

8. Rata-rata Pelayanan $(R R P)$ banyaknya pelayanan yang dapat diberikan dalam waktu tertentu.

Tabel 2 Perhitungan Kedatangan Kapal di Dermaga 5

\begin{tabular}{ccc}
\hline No. & Keterangan & Jumlah \\
\hline 1 & $\lambda$ & $486: 11=45 /$ bulan \\
2 & $\mu$ & 3 Server \\
\hline
\end{tabular}

Berikut adalah hasil dari simulasi untuk model

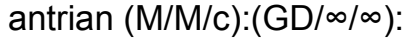

\section{Current Condition.}

a. Probabilitas tidak ada pelayanan

$$
\begin{aligned}
P_{0} & =\frac{1}{\left[\sum_{n=0}^{s-1} \frac{\left(\frac{\lambda}{\mu}\right)^{n}}{n !}\right]+\frac{\left(\frac{\lambda}{\mu}\right)^{c}}{c !\left(1-\frac{\lambda}{c \cdot \mu}\right)}} \\
& =\frac{1}{\left[\frac{\left(\frac{45}{3}\right)^{0}}{0 !}+\frac{\left(\frac{45}{3}\right)^{1}}{1 !}+\frac{\left(\frac{45}{3}\right)^{2}}{2 !}\right]+\frac{\left(\frac{45}{3}\right)^{3}}{3 !\left(1-\frac{45}{3.3}\right)}} \\
& =\frac{1}{1+15+15+4}=\frac{1}{35}=0,029
\end{aligned}
$$

b. Rata-rata jumlah menunggu dalam antrian

$$
\begin{aligned}
L_{q} & =\frac{\lambda \cdot \mu\left(\frac{\lambda}{\mu}\right)^{c}}{(c-1) !(c \cdot \mu-\lambda)^{2}} P_{0} \\
& =\frac{45 \cdot 3\left(\frac{45}{3}\right)^{3}}{(2) !(3 \cdot 3-45)^{2}} \cdot 0,029 \\
& =\frac{6.075}{144}=42,1875=43 \text { kapal }
\end{aligned}
$$

c. Rata-rata jumlah menunggu dalam sistem

$$
\begin{aligned}
L_{s} & =L_{q}+\frac{\lambda}{\mu} \\
& =43+\frac{45}{3}=58 \mathrm{kapal}
\end{aligned}
$$

d. Rata-rata waktu menunggu dalam antrian 


$$
\begin{aligned}
W_{q} & =\frac{L_{q}}{\lambda} \\
& =\frac{43}{45}=0,95555=57,33 \text { menit }
\end{aligned}
$$

e. Rata-rata waktu menunggu dalam sistem

$$
\begin{aligned}
W_{s} & =W_{q}+\frac{1}{\lambda} \\
& =0,95555+\frac{1}{45}=0,97777=58,66 \text { menit }
\end{aligned}
$$

\section{Solusi 1}

Penambahan 1 server pada dermaga dari 3 server menjadi 4 server, berikut perhitungannya:

a. Probabilitas tidak ada pelayanan?

$$
\begin{aligned}
P_{0} & =\frac{1}{\left[\sum_{n=0}^{s-1} \frac{\left(\frac{\lambda}{\mu}\right)^{n}}{n !}\right]+\frac{\left(\frac{\lambda}{\mu}\right)^{c}}{c !\left(1-\frac{\lambda}{c . \mu}\right)}} \\
& \left.=\frac{1\left(\frac{45}{4}\right)^{0}}{0 !}+\frac{\left(\frac{45}{4}\right)^{1}}{1 !}+\frac{\left(\frac{45}{4}\right)^{2}}{2 !}+\frac{\left(\frac{45}{4}\right)^{3}}{3 !}\right]+\frac{\left(\frac{45}{4}\right)^{4}}{4 !\left(1-\frac{45}{4.4}\right)} \\
& =\frac{1}{1+11,5+11,5+11,5+6}=\frac{1}{41}=0,024
\end{aligned}
$$

b. Rata-rata jumlah menunggu dalam antrian?

$$
\begin{aligned}
L_{q} & =\frac{\lambda \cdot \mu\left(\frac{\lambda}{\mu}\right)^{c}}{(c-1) !(c \cdot \mu-\lambda)^{2}} P_{0} \\
& =\frac{45 \cdot 4\left(\frac{45}{4}\right)^{4}}{(3) !(4 \cdot 4-45)^{2}} \cdot 0,024 \\
& =\frac{8.100}{174}=46,552=47 \text { kapal }
\end{aligned}
$$

c. Rata-rata jumlah menunggu dalam sistem?

$$
\begin{aligned}
L_{s} & =L_{q}+\frac{\lambda}{\mu} \\
& =47+\frac{45}{4}=58,25=59 \mathrm{kapal}
\end{aligned}
$$

d. Rata-rata waktu menunggu dalam antrian?

$$
\begin{aligned}
W_{q} & =\frac{L_{q}}{\lambda} \\
& =\frac{47}{45}=1,04444=62,66 \text { menit }
\end{aligned}
$$

e. Rata-rata waktu menunggu dalam sistem?

$$
\begin{aligned}
W_{s} & =W_{q}+\frac{1}{\lambda} \\
& =1,04444+\frac{1}{45}=1,06666=63,99 \text { menit }
\end{aligned}
$$

\section{Solusi 2}

Penambahan 2 server pada dermaga dari 3 server menjadi 5 server, berikut perhitungannya:

a. Probabilitas tidak ada pelayanan?

$$
\begin{aligned}
P_{0} & =\frac{1}{\left[\sum_{n=0}^{s-1} \frac{\left(\frac{\lambda}{\mu}\right)^{n}}{n !}\right]+\frac{\left(\frac{\lambda}{\mu}\right)^{c}}{c !\left(1-\frac{\lambda}{c . \mu}\right)}} \\
& =\frac{\left.1 \frac{\left(\frac{45}{5}\right)^{0}}{0 !}+\frac{\left(\frac{45}{5}\right)^{1}}{1 !}+\frac{\left(\frac{45}{5}\right)^{2}}{2 !}+\frac{\left(\frac{45}{5}\right)^{3}}{3 !}+\frac{\left(\frac{45}{5}\right)^{4}}{4 !}\right]+\frac{\left(\frac{45}{5}\right)^{5}}{5 !\left(1-\frac{45}{5.5}\right)}}{}=\frac{1}{1+9+9+9+9+5}=\frac{1}{42}=0,024
\end{aligned}
$$

b. Rata-rata jumlah menunggu dalam antrian?

$$
\begin{aligned}
L_{q} & =\frac{\lambda \cdot \mu\left(\frac{\lambda}{\mu}\right)^{c}}{(c-1) !(c \cdot \mu-\lambda)^{2}} P_{0} \\
& =\frac{45 \cdot 5\left(\frac{45}{5}\right)^{5}}{(4) !(5 \cdot 5-45)^{2}} \cdot 0,024 \\
& =\frac{10.125}{400}=25,312=26 \mathrm{kapal}
\end{aligned}
$$

c. Rata-rata jumlah menunggu dalam sistem?

$$
\begin{aligned}
L_{s} & =L_{q}+\frac{\lambda}{\mu} \\
& =26+\frac{45}{5}=35 \mathrm{kapal}
\end{aligned}
$$

d. Rata-rata waktu menunggu dalam antrian?

$$
\begin{aligned}
W_{q} & =\frac{L_{q}}{\lambda} \\
& =\frac{26}{45}=0,57777=34,66 \text { menit }
\end{aligned}
$$

e. Rata-rata waktu menunggu dalam sistem?

$$
\begin{aligned}
W_{s} & =W_{q}+\frac{1}{\lambda} \\
& =0,57777+\frac{1}{45}=0,59999=35,99 \text { menit }
\end{aligned}
$$

Setelah melakukan observasi dan pengolahan data maka di dapatkan hasil perhitungan yang optimum waktu tunggu antrian (Wq) 4 server > waktu tunggu antrian (Wq) 5 server. Hal menyatakan bahwa kapal yang bertambat di dermaga 5 dengan banyaknya kapal $45 \mathrm{kapal} / \mathrm{bulan}$ dengan jumlah server melayani kapal yang akan bertambat dari sebelumnya 3 server harus ditambah menjadi 5 server pada dermaga 5 di PT. Pelabuhan Indonesia II (Persero) Cabang Banten, dengan begitu maka di dapatkan rata-rata waktu optimum antrian pada solusi 2 yaitu 34,66 menit dan waktu menunggu rata-rata dalam sistem pelayanan solusi 2 adalah 35,99 menit. Sehingga 
didapatkan penurunan waktu yang optimum di dermaga 5 dengan rata-rata waktu dalam antrian sebesar 28 menit dan serta waktu menunggu rata-rata dalam sistem pelayanan 28 menit.

\section{KESIMPULAN}

Dari hasil pembahasan pada bab IV diperoleh bahwa banyaknya kedatangan kapal pada stasiun dermaga di Pelabuhan Indonesia II Cabang Ciwandan mengikuti distribusi poisson dan distribusi waktu pelayanan mengikuti distribusi general sehingga didapat model antrian (M/M/c): $(\mathrm{GD} / \infty / \infty)$ dengan rata-rata waktu antar kedatangan $(\mathrm{Wq})=57,33$ Menit dan waktu ratarata pelayanan $(\mathrm{Ws})=58,66$ Menit. Waktu menunggu dalam antrian (Lq) $=43$ kapal. Berdasarkan hasil perhitungan pada dermaga 5 , hasil yang optimum adalah menambahkan 2 server, dari 3 server menjadi 5 server dikarenakan dari perhitungan 5 server didapat rata-rata waktu menunggu dalam antrian $(\mathrm{Wq})=$ 34, 66 Menit dan rata-rata waktu menunggu dalam sistem $(\mathrm{Ws})=35,99$ menit.

\section{DAFTAR PUSTAKA}

Baroto, T. (2010). Penentuan Jumlah Operator Bagian Packing dengan Menggunakan Metode Antrian Guna Mengurangai Waktu Tunggu dan Biaya. Jurnal Teknik Industri, 1(1), 50-59

Bronson, R. (1993). Teori dan Soal-soal Operation Research. Jakarta : Erlangga.

Harahap, S. A. R., Sinulingga, U., \& Ariswoyo, S. (2014). Analisis Sistem Antrian Pelayanan Nasabah di PT. Bank Negara Indonesia (Persero) TBK Kantor Cabang Utama USU. Saintia Matematika, 2(3), 277-287.

Levin, R. I. et. al. (2002). Pengambilan Keputusan Secara Kuantitatif. Edisi Ketujuh. Diterjemahkan oleh Nartanto. Jakarta: Raja Grafindo Persada.

Sari, A. N. (2013). Model Sistem Antrian Pesawat Terbang di Bandara Internasional Adisutjipto Yogyakarta. Gamatika, 2(1).1624

Subagyo, P., Asri, M., \& Handoko, T.H. (1938). Dasar-dasar Oprasion Research Edisi 2. Yogyakarta : BPFE.

Tinambunan, A. P. (2017). Analisis Sistem Antrian pada Stasiun Pengisian Bahan Bakar (SPBU) Kopkar Nusa Tiga Jl. Sunggal Medan. Jurnal Manajemen dan Bisnis, 16(1), 14-34. 